\title{
Comparing Stagonosporopsis spp. Fungicide Resistance Profiles in Florida and East China Cucurbit Production Systems
}

\author{
Mason J. Newark, ${ }^{1}$ Pingfang $\mathrm{Li}^{2}{ }^{2}$ Xing-Ping Yang, ${ }^{2}$ Mathews L. Paret, ${ }^{1,3, \dagger}$ and Nicholas S. Dufault ${ }^{1, \dagger}$ \\ ${ }^{1}$ Department of Plant Pathology, University of Florida, Gainesville, FL 32611-0680, U.S.A. \\ 2 Jiangsu Academy of Agricultural Sciences, Nanjing, China \\ ${ }^{3}$ North Florida Research and Education Center, University of Florida, Quincy, FL 32351, U.S.A.
}

\begin{abstract}
Gummy stem blight, caused by Stagonosporopsis spp., is a major disease of cucurbits in the United States and China that is managed primarily through the use of fungicides. The objective of this study was to monitor and compare the recent fungicide resistance profiles of Stagonosporopsis spp. in Florida open-field and East China protected-structure production systems. Isolates of Stagonosporopsis spp. were evaluated for sensitivity to the commonly used fungicides azoxystrobin, boscalid, tebuconazole, and thiophanate-methyl at discriminatory rates of 0.096, 0.034, 0.128, and $100 \mathrm{mg} / \mathrm{liter}$, respectively. Isolates were collected from Jiangsu,

of isolates from Florida and East China were resistant to thiophanatemethyl. Boscalid resistance was detected in both isolate collections but was two times more frequent in China. Resistance to azoxystrobin was detected in $66 \%$ of isolates in Florida but only $7 \%$ in China. Tebuconazole was effective in controlling the mycelia growth of Stagonosporopsis spp. in both collections. The results indicate that both production systems currently face similar challenges related to the development of fungicide resistance in Stagonosporopsis spp. However, the resistance profiles are unique for both production systems.
\end{abstract} Jiangxi, Zhejiang, and Anhui provinces in China $(n=69), 12$ counties in Florida $(n=89)$, and one county in Georgia $(n=6)$. More than $50 \%$
Keywords: chemical, disease management, fungi, vegetables
Gummy stem blight (GSB) is a major disease of all cucurbits throughout the world, including in Florida and East China (Babu et al. 2015; Keinath 2011; Kothera et al. 2003; Li et al. 2014; Sitterly and Keinath 1996). This disease can cause yield losses of $>60 \%$ in watermelon by defoliation and fruit rot (Keinath 2000). The causal agents of this disease include three morphologically identical but genetically distinct species of Stagonosporopsis spp.: S. citrulli, S. cucurbitacearum (syn. Didymella bryoniae), and S. caricae (Stewart et al. 2015). These pathogens are facultative necrotrophs and homothallic (Chiu 1949; Chiu and Walker 1949) and are known to be seedborne (Hopkins et al. 2003; Lee et al. 1984), but they can also survive on decaying crop debris and weed hosts (Keinath 2002). Dispersal within a field typically occurs by splash from rainfall, irrigation, and pesticide sprays. Dispersal between fields and on a continental scale can occur through windborne ascospores or seed infections (Café-Filho et al. 2010; Hopkins et al. 2003; Keinath and DuBose 2017; Sudisha et al. 2006).

U.S. fresh market cucurbit production is often an open-field system that typically uses polyethylene mulch and drip or overhead irrigation. Planting seasons can start as early as January in South

Current address of M. J. Newark: AMVAC Chemical Corporation, Newport Beach, CA, U.S.A.

${ }^{\dagger}$ Corresponding authors: N. S. Dufault and M. L. Paret; nsdufault@ufl.edu and paret@ufl.edu

Funding: This study was conducted with funding from the National Watermelon Association and the Natural Sciences Foundation of China. The Jiangsu Academy of Agricultural Sciences provided visiting student funding, which enabled M. Newark to conduct studies in East China.

*The $\boldsymbol{e}$-Xtra logo stands for "electronic extra" and indicates that one supplementary figure is published online.

The author(s) declare no conflict of interest.

Accepted for publication 26 July 2019.

C 2020 The American Phytopathological Society
Florida and continue through the summer. The open system is economical, since high labor demands and costs are only required around planting and harvest. Early plantings in Florida are preferred because this commands better market prices and can avoid certain plant pathogens (Elwakil et al. 2017). Although there are disease resistance cultivars available for anthracnose (Colletotrichum orbiculare) and powdery mildew (Erysiphe cichoracearum), currently there are no commercial cultivars with resistance to GSB available (Elwakil et al. 2017; Gusmini et al. 2005; Paret et al. 2014). Thus, fungicides are frequently used to manage pathogens, such as GSB, making them a key component of U.S. watermelon production systems.

In contrast, there are multiple regions in China's fresh market cucurbit production that grow watermelons using protected structures. Drip irrigation and polyethylene mulch are also used in this production system. Although this system tends to be more labor-intensive because of the protected structures, the result is that rain splash is eliminated in many production fields. This drastic reduction in rain splash also eliminates localized spread of some foliar pathogens. Despite this possible disease pressure reduction, fungicides are still used extensively in Chinese production systems $(\mathrm{Li}$, personal communication). There are several reasons for this overuse of pesticides. In a 2008 survey, $69 \%$ of growers applied pesticides whenever pests were observed, regardless of the amount of damage these pests were causing. Another $27 \%$ of growers applied chemical pesticides in a prophylactic manner, citing that they believed a pest would arrive soon. The remaining $4 \%$ of respondents cited a notification by an agriculture technician $(1 \%)$ or that neighbors had reported the pest $(3 \%)$ (Xu et al. 2008). In fact, Chinese agricultural production has become increasingly reliant on chemical pesticides for disease and pest control, leading to the development of insecticide resistance in pests (Pan 2015).

Fungicides are a primary in-season management tool for both production systems; consequently, fungicide resistance is a risk. The identification of fungicide resistance in U.S. Stagonosporopsis spp. has been well documented, but there is limited information from Chinese production systems. Resistance to thiophanate-methyl, a methyl benzimidazole carbamate (MBC), was first reported for the United States in 1995 (Keinath and Zitter 1998), followed by the quinone outside inhibitor (QoI) fungicide, azoxystrobin, in 2002 (Stevenson 
et al. 2004); succinate dehydrogenase inhibitor (SDHI) resistance for boscalid was confirmed in 2007 (Stevenson et al. 2008; Thomas et al. 2012). Resistance to demethylation inhibitor (DMI) fungicides has been reported ( $\mathrm{Li}$ et al. 2016), but this has been less frequent compared with other classes of fungicides (Keinath and Hansen 2013). Currently, Stagonosporopsis spp. fungicide resistance in China is not documented. With only a limited number of fungicides available for managing GSB and the fact that a majority (>30\%) of U.S. watermelon seed imports come from China as indicated by the U.S. Department of Agriculture Economic Research Service in 2013, it is important to monitor resistance in the U.S. and China production systems.

Given the uniqueness of these two production systems, selection pressure from fungicide applications should vary between them. Thus, we hypothesized that although fungicide resistance would be present in both systems, lower incidences of resistance isolates would be present in the protected system of East China compared with the open production system of Florida. The objectives of this study were as follows: (i) to monitor the prevalence of resistant isolates to four fungicide classes from 2010 to 2016 collections in a major production region of Florida and Georgia (which will be referred to as Florida isolates from here onward) and East China; (ii) to assess for changes in these distributions within the regions and the incidence of inhibition over time; and (iii) to compare the resistant isolate incidence distributions of the fungicides between the two regions. Insights from this study will be used for outlining

Table 1. Collection information for East China Stagonosporopsis spp. isolates with their reference number (isolate), Stagonosporopsis sp. identification (species), collection year, and the province and prefecture location

\begin{tabular}{|c|c|c|c|c|}
\hline Isolate & Species $^{\mathbf{a}}$ & Collection year & Province & Prefecture \\
\hline$\overline{c h 1}$ & Not tested & 2012 & Jiangxi & Jiujiang \\
\hline $\operatorname{ch} 2$ & S. citrulli & 2012 & Jiangxi & Jiujiang \\
\hline $\operatorname{ch} 3$ & S. citrulli & 2012 & Jiangsu & Xuzhou \\
\hline $\operatorname{ch} 4$ & Not tested & 2012 & Jiangsu & Xuzhou \\
\hline $\operatorname{ch} 5$ & S. citrulli & 2012 & Jiangsu & Xuzhou \\
\hline $\operatorname{ch} 6$ & S. citrulli & 2012 & Jiangsu & Xuzhou \\
\hline $\operatorname{ch} 7$ & S. citrulli & 2012 & Zhejiang & Ningbo \\
\hline $\operatorname{ch} 8$ & S. citrulli & 2012 & Zhejiang & Ningbo \\
\hline $\operatorname{ch} 9$ & S. citrulli & 2012 & Zhejiang & Ningbo \\
\hline $\operatorname{ch} 10$ & S. citrulli & 2012 & Zhejiang & Ningbo \\
\hline $\operatorname{ch} 11$ & S. citrulli & 2012 & Zhejiang & Ningbo \\
\hline $\operatorname{ch} 12$ & S. citrulli & 2012 & Zhejiang & Ningbo \\
\hline $\operatorname{ch} 13$ & S. cucurbitacearum & 2012 & Zhejiang & Ningbo \\
\hline $\operatorname{ch} 14$ & S. citrulli & 2012 & Zhejiang & Ningbo \\
\hline $\operatorname{ch} 15$ & Not tested & 2012 & Zhejiang & Ningbo \\
\hline $\operatorname{ch} 16$ & S. citrulli & 2012 & Zhejiang & Ningbo \\
\hline $\operatorname{ch} 17$ & S. citrulli & 2012 & Zhejiang & Ningbo \\
\hline $\operatorname{ch} 18$ & S. citrulli & 2012 & Zhejiang & Ningbo \\
\hline $\operatorname{ch} 19$ & S. citrulli & 2012 & Jiangsu & Wuxi \\
\hline $\operatorname{ch} 20$ & S. citrulli & 2012 & Jiangsu & Wuxi \\
\hline $\operatorname{ch} 21$ & S. citrulli & 2012 & Jiangsu & Wuxi \\
\hline $\operatorname{ch} 22$ & Not tested & 2012 & Jiangsu & Wuxi \\
\hline $\operatorname{ch} 23$ & S. citrulli & 2012 & Jiangsu & Wuxi \\
\hline $\operatorname{ch} 24$ & S. citrulli & 2012 & Jiangsu & Wuxi \\
\hline $\operatorname{ch} 25$ & S. citrulli & 2012 & Jiangsu & Wuxi \\
\hline $\operatorname{ch} 26$ & Not tested & 2012 & Jiangsu & Nantong \\
\hline $\operatorname{ch} 27$ & S. citrulli & 2012 & Jiangsu & Nantong \\
\hline $\operatorname{ch} 28$ & S. citrulli & 2012 & Jiangsu & Nantong \\
\hline $\operatorname{ch} 29$ & S. citrulli & 2012 & Jiangsu & Zhenjiang \\
\hline $\operatorname{ch} 30$ & S. citrulli & 2012 & Jiangsu & Zhenjiang \\
\hline $\operatorname{ch} 31$ & S. citrulli & 2012 & Jiangsu & Zhenjiang \\
\hline $\operatorname{ch} 32$ & S. citrulli & 2012 & Jiangsu & Zhenjiang \\
\hline $\operatorname{ch} 33$ & S. citrulli & 2012 & Jiangsu & Nanjing \\
\hline $\operatorname{ch} 34$ & S. citrulli & 2012 & Jiangsu & $\begin{array}{l}\text { Nanjing } \\
\text { (Continued) }\end{array}$ \\
\hline
\end{tabular}

\footnotetext{
${ }^{\text {a }}$ Species were determined using a multiplex reaction consisting of three
} microsatellite markers (Db01,Db05, and Db06) (Brewer et al. 2015). fungicide recommendations for Florida and East China producers, while establishing a baseline for common fungicides in China.

\section{Materials and Methods}

Single spore isolation and collection. Sixty-nine isolates were collected between 2012 and 2015 in four major fresh market melon and watermelon provinces in East China (Table 1; Supplementary Fig. S1). A total of 89 isolates from watermelon and other cucurbits were collected from major fresh market watermelon production counties in Florida between 2010 and 2016 (Table 2). An additional six isolates from Tift County, Georgia, collected in 2011 from watermelon were also included in this study (Table 2). All isolates originated from a single conidium using the following method. Spore suspensions were collected from 10-day-old cultures grown on quarter-strength potato dextrose agar (QPDA) consisting of $3.8 \mathrm{~g}$ of potato dextrose agar and $2.5 \mathrm{~g}$ of granulated agar dissolved in $500 \mathrm{ml}$ of deionized water (Qingdao Hope Bio-Technology Co. Ltd., Nanjing, China; and Becton, Dickinson, and Company, Sparks, MD). Using a $1 \%$ Tween 20 solution, plates were scraped to release spores, and the suspension was collected into microcentrifuge tubes. The suspension concentration was calculated using a hemacytometer under a compound microscope at $40 \times$ magnification and was ad+justed to $1 \times 10^{3}$ spores $/ \mathrm{ml}$. Two-microliter aliquots were dropped onto $2 \%$ water agar plates on predetermined areas. The droplets were allowed to dry and germinated spores were observed after $24 \mathrm{~h}$ under a compound microscope at $40 \times$ magnification for germ tubes. Areas containing one spore were then removed and transferred to a QPDA

Table 1. (Continued)

\begin{tabular}{|c|c|c|c|c|}
\hline Isolate & Species $^{\mathbf{a}}$ & Collection year & Province & Prefecture \\
\hline $\operatorname{ch} 35$ & S. citrulli & 2012 & Jiangsu & Nanjing \\
\hline $\operatorname{ch} 36$ & S. citrulli & 2012 & Jiangsu & Zhenjiang \\
\hline $\operatorname{ch} 37$ & S. citrulli & 2012 & Jiangsu & Zhenjiang \\
\hline $\operatorname{ch} 38$ & S. citrulli & 2012 & Jiangsu & Nanjing \\
\hline ch39 & S. citrulli & 2012 & Jiangsu & Nanjing \\
\hline ch40 & S. citrulli & 2012 & Jiangsu & Nanjing \\
\hline $\operatorname{ch} 41$ & S. citrulli & 2012 & Jiangsu & Nanjing \\
\hline $\operatorname{ch} 42$ & S. citrulli & 2012 & Anhui & Hefei \\
\hline $\operatorname{ch} 43$ & S. citrulli & 2012 & Anhui & Hefei \\
\hline $\operatorname{ch} 44$ & S. citrulli & 2013 & Jiangsu & Nantong \\
\hline $\operatorname{ch} 45$ & S. citrulli & 2013 & Jiangsu & Nantong \\
\hline $\operatorname{ch} 46$ & Not tested & 2013 & Jiangsu & Nantong \\
\hline $\operatorname{ch} 47$ & S. citrulli & 2013 & Jiangsu & Nanjing \\
\hline $\operatorname{ch} 48$ & S. citrulli & 2014 & Jiangsu & Huaian \\
\hline $\operatorname{ch} 49$ & S. citrulli & 2014 & Jiangsu & Huaian \\
\hline $\operatorname{ch} 50$ & Not tested & 2014 & Jiangsu & Huaian \\
\hline $\operatorname{ch} 51$ & S. citrulli & 2014 & Jiangsu & Huaian \\
\hline ch52 & S. caricae & 2014 & Jiangsu & Huaian \\
\hline $\operatorname{ch} 53$ & S. caricae & 2014 & Jiangsu & Huaian \\
\hline $\operatorname{ch} 54$ & S. citrulli & 2014 & Jiangsu & Huaian \\
\hline ch55 & Not tested & 2014 & Jiangsu & Huaian \\
\hline ch56 & S. citrulli & 2014 & Jaingsu & Suzhou \\
\hline $\operatorname{ch} 57$ & Not tested & 2014 & Jaingsu & Suzhou \\
\hline $\operatorname{ch} 58$ & S. citrulli & 2014 & Jaingsu & Suzhou \\
\hline $\operatorname{ch} 59$ & S. citrulli & 2014 & Jaingsu & Suzhou \\
\hline ch60 & S. citrulli & 2014 & Jaingsu & Suzhou \\
\hline ch61 & S. citrulli & 2014 & Jaingsu & Suzhou \\
\hline $\operatorname{ch} 62$ & S. citrulli & 2014 & Jaingsu & Suzhou \\
\hline ch63 & S. citrulli & 2012 & Anhui & Hefei \\
\hline ch64 & S. citrulli & 2012 & Anhui & Hefei \\
\hline $\operatorname{ch} 65$ & S. citrulli & 2012 & Jiangsu & Nanjing \\
\hline ch66 & S. citrulli & 2014 & Jiangsu & Suzhou \\
\hline ch67 & S. citrulli & 2014 & Jiangsu & Suzhou \\
\hline $\operatorname{ch} 68$ & S. citrulli & 2012 & Jiangsu & Zhenjiang \\
\hline $\operatorname{ch} 71$ & Not tested & 2015 & Jiangsu & Yancheng \\
\hline
\end{tabular}


plate. The Florida isolates were stored on desiccated filter paper at $-20^{\circ} \mathrm{C}$, whereas the East China isolates were stored on agar slants at $4{ }^{\circ} \mathrm{C}$.

Select isolate species determination. Genomic DNA was extracted from isolates ( $n=44$ and 50 for China and Florida, respectively) using the Qiagen DNeasy Plant Mini Kit (Qiagen, Venlo, The Netherlands) according to the manufacturer's instructions. Fresh tissue (100 mg) was macerated using liquid nitrogen and a micropestle. Final DNA concentrations were confirmed using a NanoDrop spectrophotometer (model 2000, version 1.0; Thermo Scientific, Waltham, MA). Extracted DNA was then stored at $-20^{\circ} \mathrm{C}$ until ready for use. A multiplex reaction consisting of three microsatellite markers ( $D b 01, D b 05$, and $D b 06$ ) was used to determine the species (Brewer et al. 2015). PCR was conducted using $12.5 \mu$ l of DreamTaq master mix (Thermo Scientific), $1.25 \mu \mathrm{l}$ of each primer (Integrated DNA Technologies), and $1 \mu \mathrm{l}$ of template DNA and $4 \mu \mathrm{l}$ of moleculargrade water (Thermo Scientific). Thermal cycling conditions were $94^{\circ} \mathrm{C}$ for $2 \mathrm{~min} ; 40$ cycles of $94^{\circ} \mathrm{C}$ for $30 \mathrm{~s}, 55^{\circ} \mathrm{C}$ for 30 s, and $72^{\circ} \mathrm{C}$ for $30 \mathrm{~s}$; followed by $72^{\circ} \mathrm{C}$ for $5 \mathrm{~min}$. Amplification of PCR products was confirmed on $2.5 \%$ (wt/vol) agarose gel.

In vitro assay for fungicide resistance. Fungicide resistance was assessed using an amended agar assay consistent with previous studies (Keinath 2009; Keinath and Zitter 1998; Thomas et al. 2012). Five fungicides were tested for the China isolates, including azoxystrobin (Quadris; Syngenta), boscalid (Endura; Bayer), difenoconazole (Inspire; Syngenta), tebuconazole (Tebustar; Agristar), and thiophanate-methyl (Topsin M; United Phosphorus Inc.). Florida isolates were tested against four classes of fungicides, which include the aforementioned treatments, excluding difenoconazole. The same rates and procedure were used for the four fungicides. Commercial formulations of the aforementioned fungicides were mixed into QPDA at respective rates of 0.096 (azoxystrobin), 0.034 (boscalid), 0.032 (difenoconazole), and $0.128 \mathrm{mg} /$ liter (tebuconazole). These fungicides and their respective rates represent discriminatory dosages
Table 2. Collection information for Florida Stagonosporopsis spp. isolates with their reference number (isolate), Stagonosporopsis sp. identification (species), collection year, and the state and county location

\begin{tabular}{|c|c|c|c|c|}
\hline Isolate & Species $^{\text {a }}$ & Collection year & State & County \\
\hline 1 & S. citrulli & 2011 & Georgia & Tift \\
\hline 2 & Not tested & 2011 & Georgia & Tift \\
\hline 4 & S. citrulli & 2011 & Georgia & Tift \\
\hline 5 & S. citrulli & 2011 & Georgia & Tift \\
\hline 7 & S. citrulli & 2011 & Georgia & Tift \\
\hline 8 & S. citrulli & 2011 & Georgia & Tift \\
\hline 9 & S. citrulli & 2011 & Florida & Santa Rosa \\
\hline 11 & Not tested & 2011 & Florida & Santa Rosa \\
\hline 18 & S. citrulli & 2011 & Florida & Santa Rosa \\
\hline 24 & Not tested & 2011 & Florida & Santa Rosa \\
\hline 25 & S. citrulli & 2011 & Florida & Santa Rosa \\
\hline 27 & Not tested & 2011 & Florida & Santa Rosa \\
\hline 33 & S. citrulli & 2012 & Florida & Gadsden \\
\hline 35 & Not tested & 2012 & Florida & Gadsden \\
\hline 36 & S. caricae & 2012 & Florida & Gadsden \\
\hline 40 & S. citrulli & 2012 & Florida & Alachua \\
\hline 41 & S. citrulli & 2012 & Florida & Marion \\
\hline 43 & Not tested & 2012 & Florida & Marion \\
\hline 603 & S. citrulli & 2011 & Florida & Alachua \\
\hline 911 & S. citrulli & 2004 & Florida & Alachua \\
\hline 1201 & S. caricae & 2012 & Florida & Putnam \\
\hline 1412 & S. citrulli & 2014 & Florida & Gadsden \\
\hline 1413 & S. citrulli & 2014 & Florida & Levy \\
\hline 1414 & S. caricae & 2014 & Florida & Levy \\
\hline 1415 & S. citrulli & 2014 & Florida & Levy \\
\hline 1416 & S. citrulli & 2014 & Florida & Levy \\
\hline 1419 & Not tested & 2014 & Florida & Levy \\
\hline 1420 & Not tested & 2014 & Florida & Levy \\
\hline 1422 & S. citrulli & 2014 & Florida & Levy \\
\hline 1423 & S. citrulli & 2014 & Florida & Levy \\
\hline 1424 & Not tested & 2014 & Florida & Madison \\
\hline 1427 & S. citrulli & 2014 & Florida & Madison \\
\hline 1428 & Not tested & 2014 & Florida & Madison \\
\hline 1432 & S. citrulli & 2014 & Florida & Union \\
\hline 1437 & S. citrulli & 2014 & Florida & Union \\
\hline 1441 & S. citrulli & 2014 & Florida & Madison \\
\hline 1443 & S. citrulli & 2014 & Florida & Madison \\
\hline 1445 & S. citrulli & 2014 & Florida & Madison \\
\hline 1460 & S. citrulli & 2014 & Florida & Madison \\
\hline 1471 & Not tested & 2014 & Florida & Madison \\
\hline 1474 & Not tested & 2014 & Florida & Madison \\
\hline 1477 & Not tested & 2014 & Florida & Madison \\
\hline 1478 & Not tested & 2014 & Florida & Madison \\
\hline 1479 & Not tested & 2014 & Florida & $\begin{array}{l}\text { Madison } \\
\text { (Continued) }\end{array}$ \\
\hline
\end{tabular}

${ }^{a}$ Species were determined using a multiplex reaction consisting of three microsatellite markers (Db01,Db05, and Db06) (Brewer et al. 2015).
Table 2. (Continued)

\begin{tabular}{|c|c|c|c|c|}
\hline Isolate & Species $^{\mathbf{a}}$ & Collection year & State & County \\
\hline 1483 & S. citrulli & 2014 & Florida & Madison \\
\hline 1485 & S. citrulli & 2014 & Florida & Madison \\
\hline 1494 & S. citrulli & 2014 & Florida & Union \\
\hline 1503 & Not tested & 2015 & Florida & Sumter \\
\hline 1505 & S. citrulli & 2015 & Florida & Sumter \\
\hline 1506 & Not tested & 2015 & Florida & Sumter \\
\hline 1510 & S. citrulli & 2015 & Florida & Sumter \\
\hline 1514 & S. citrulli & 2015 & Florida & Sumter \\
\hline 1515 & Not tested & 2015 & Florida & Sumter \\
\hline 1521 & Not tested & 2015 & Florida & Jackson \\
\hline 1533 & Not tested & 2015 & Florida & Gadsden \\
\hline 1534 & Not tested & 2015 & Florida & Gadsden \\
\hline 1536 & Not tested & 2015 & Florida & Gadsden \\
\hline 1608 & S. citrulli & 2016 & Florida & Hendry \\
\hline $12 \mathrm{~A}$ & S. citrulli & 2011 & Florida & Santa Rosa \\
\hline $12 \mathrm{~B}$ & S. citrulli & 2011 & Florida & Santa Rosa \\
\hline $13 \mathrm{~B}$ & S. citrulli & 2011 & Florida & Santa Rosa \\
\hline $1442 \mathrm{~A}$ & S. citrulli & 2014 & Florida & Madison \\
\hline $1443 a$ & S. citrulli & 2014 & Florida & Madison \\
\hline $1457 \mathrm{a}$ & S. citrulli & 2014 & Florida & Madison \\
\hline 1457B & S. citrulli & 2014 & Florida & Madison \\
\hline $1462 \mathrm{~A}$ & Not tested & 2014 & Florida & Madison \\
\hline $1462 B$ & Not tested & 2014 & Florida & Madison \\
\hline $1466 \mathrm{~A}$ & S. citrulli & 2014 & Florida & Madison \\
\hline 1466B & S. citrulli & 2014 & Florida & Madison \\
\hline 1467B & S. citrulli & 2014 & Florida & Madison \\
\hline $1469 \mathrm{~A}$ & Not tested & 2014 & Florida & Madison \\
\hline 1469B & Not tested & 2014 & Florida & Madison \\
\hline 1473B & Not tested & 2014 & Florida & Madison \\
\hline $1485 \mathrm{~A}$ & S. citrulli & 2014 & Florida & Madison \\
\hline $1501 \mathrm{~A}$ & S. citrulli & 2015 & Florida & Sumter \\
\hline 1501B & S. citrulli & 2015 & Florida & Sumter \\
\hline $1504 \mathrm{~A}$ & S. citrulli & 2015 & Florida & Sumter \\
\hline 1504B & S. citrulli & 2015 & Florida & Sumter \\
\hline 1605B & S. citrulli & 2016 & Florida & Collier \\
\hline $1611 \mathrm{~A}$ & S. citrulli & 2016 & Florida & Hendry \\
\hline 1605B & S. citrulli & 2016 & Florida & Collier \\
\hline $1606 \mathrm{~A}$ & S. citrulli & 2016 & Florida & Collier \\
\hline $1612 \mathrm{~A}$ & S. citrulli & 2016 & Florida & Hendry \\
\hline 1615B & S. citrulli & 2016 & Florida & Hendry \\
\hline $19 \mathrm{~A}$ & S. citrulli & 2011 & Florida & Santa Rosa \\
\hline 19B & S. citrulli & 2011 & Florida & Santa Rosa \\
\hline $23 \mathrm{~A}$ & S. citrulli & 2011 & Florida & Santa Rosa \\
\hline $23 \mathrm{~B}$ & S. citrulli & 2011 & Florida & Santa Rosa \\
\hline $30 \mathrm{~A}$ & S. citrulli & 2011 & Florida & Jackson \\
\hline $30 \mathrm{~B}$ & S. citrulli & 2011 & Florida & Jackson \\
\hline
\end{tabular}


based on baseline half maximal effective concentration values established in the United States from previous studies (Keinath 2009; Thomas et al. 2012). For thiophanate-methyl, an arbitrary rate of $100 \mathrm{mg} / \mathrm{liter}$ was chosen, based on previous studies (Keinath and Zitter 1998). Stock solutions of each fungicide were added to the agar after it had cooled to $60^{\circ} \mathrm{C}$ and were swirled for $15 \mathrm{~s}$ to ensure proper mixing. Plates were poured within 5 min of swirling and were cooled at room temperature $\left(20\right.$ to $\left.30^{\circ} \mathrm{C}\right)$. In addition to the fungicide amendments, all plates were also amended with the antibiotic chloramphenicol at a rate of $50 \mathrm{mg} / \mathrm{liter}$. Two controls were used; the first consisted of fungicide-free QPDA, whereas the second control was the same fungicide-free QPDA with salicylhydroxamic acid (SHAM). SHAM was added from a stock solution of $100 \mathrm{mg} / \mathrm{liter}$ dissolved in $50 \mathrm{ml}$ of $99 \%$ ethanol. The fungicide-free QPDA was used to compare the thiophanate-methyl, tebuconazole, difenoconazole, and boscalid treatments. The SHAM-amended QPDA served as a control for the azoxystrobin treatment.

A 6-mm agar plug from the edge of 5- to 7-day-old pure culture was transferred mycelial side down in a laminar flow hood onto an amended QPDA plate. These plates were then stored at $22 \pm 2.5^{\circ} \mathrm{C}$ in complete darkness. Radial growth, consisting of two perpendicular radii starting at the center of the agar plug, was taken at 48,72 , and $96 \mathrm{~h}$ for each plate, with the 96-h timepoint being considered the



Fig. 1. A, Phenotype resistance response for Florida isolates $(n=89$ for Florida, $n=6$ for Georgia) to the various fungicide treatments from a mycelial growth assay. B, Phenotype resistance response for East China isolates $(n=69)$ to the various fungicide treatments from a mycelial growth assay. The percentage of the isolates exhibiting the various resistant phenotype is on the $x$-axis and fungicide product is on the $y$-axis. Resistant isolates are classified as having a mycelial inhibition of $<10 \%$. Reduced isolates are classified as having any mycelial inhibition $>10 \%$ but $<40 \%$. Sensitive isolates are classified as having a $>40 \%$ mycelial inhibition to the fungicidal treatment. The fungicides used are listed on the $y$-axis, with thiophanatemethyl denoted at thiophanate-M. The azoxystrobin treatment was amended with $100 \mathrm{mg} /$ liter of salicylhydroxamic acid. endpoint. The radius of the control (ctrl) was divided by the radius of the treatment (trt) and multiplied by 100 to find the percent inhibition using the following formula:

$$
\text { Percent inhibition }=\left(1-\left(\frac{\text { Radius }_{\text {trt }}}{\text { Radius }_{\text {ctrl }}}\right)\right) \times 100
$$

Based on percent inhibition values, isolates were classified into three categories: sensitive ( $>40 \%$ inhibition), reduced sensitivity $(<40 \%$ but $>10 \%$ inhibition), or resistant $(<10 \%$ inhibition). Studies on the Florida isolates were repeated twice with three technical replicates. Because of time limitations and a lack of equipment, isolates in China were technically replicated three times to produce mean inhibition values used in distribution analysis.

Statistical analysis. Statistical analysis was completed using the base package of $\mathrm{R}$ (version 2.3.3). The Kolmogorov-Smirnov test (empirical distribution function, ks.test; R Core Team 2015) was used to examine the relationship between Florida and China mean percent inhibition distributions (Chakravarti et al. 1967; Conover 1999). These distribution relationships were visualized using kernel density plots [sm.density.compare()] (R Core Team 2015). All distributions were assessed for normality using a Shapiro-Wilk test for normality (Royston 1982a, b). A Pearson correlation test was conducted on mean percent inhibitions by year collected, and between tebuconazole and difenoconazole mean percent inhibitions for the China collection to assess cross-resistance (Sedgwick 2012). A McNemar test was also conducted on the same fungicide phenotypes to further assess cross-resistance (Agresti 2007).

\section{Results}

Boscalid. Boscalid resistance was observed in 41 of 95 Florida isolates and in 67 of 69 East China isolates. Another 27 isolates from the Florida collection exhibited some level of reduced sensitivity. The remaining three isolates in both collections were classified as sensitive (Fig. 1). The Shapiro-Wilk test indicated that the percent inhibition distributions for the isolates were not normally distributed for Florida (W $=0.912, P<0.0001)$ and China $(\mathrm{W}=0.771, P<$ $0.0001)$. The distributions between the two systems were significantly different from each other ( $\mathrm{D}=0.525, P<0.0001$ ) (Fig. 2). For the East China isolates, there was a weak correlation between the year collected and mean percent inhibition $(R=0.19, P=$ 0.1030). However, for the Florida isolates, there was a significant correlation between year collected and mean percent inhibition $(R=$ $-0.36, P=0.0006$ ) (Fig. 3).

Tebuconazole. A majority of isolates were sensitive to tebuconazole, with 65 of 95 isolates in Florida and 37 of 69 isolates in East China exhibiting this phenotype. Reduced sensitivity was observed in both collections, with $20 \%$ of isolates $(n=19)$ exhibiting this phenotype in the Florida collection. Thirty-eight percent of East China isolates $(n=26)$ also exhibited the reduced sensitivity phenotype. A total of three and six isolates were resistant to tebuconazole in the Florida and East China collections, respectively (Fig. 1). Of the nine isolates identified as resistant, six (1412, ch5, ch6, ch12, ch30, and ch35) were identified as $S$. citrulli (Tables 1 and 2). The distributions of the mean percent inhibition for this product peaked around $50 \%$, with a long tail to the left, and were not normally distributed $(\mathrm{W}=0.360, P<0.0001$ for Florida; $\mathrm{W}=0.751, P<$ 0.0001 for East China). Comparisons of the isolates' mean percent inhibition responses in each region indicated that the distributions were the same ( $\mathrm{D}=0.162, P=0.2300)$ (Fig. 2). Linear correlation analysis of the mean percent inhibition compared with isolate collection date indicated that these two factors were not linearly related $(R=-0.165, P=0.1260$ for Florida; $R=0.015, P=0.9000$ for East China) (Fig. 3).

Azoxystrobin. Sixty-three percent of Florida isolates (60 of 95) were phenotyped to be resistant to azoxystrobin and $92 \%$ of East China isolates (64 of 69) were sensitive to this fungicide (Fig. 1). The distributions of percent inhibition clustered around $0 \%$ for the Florida isolates and $50 \%$ for the East China isolates. Long tails were present on both distributions, indicating that a small percentage $(<30 \%)$ exhibited the opposite phenotypes for these two isolate 
collections, which led to non-normal distributions for both regions (W $=0.795, P<0.0001$ for Florida; $\mathrm{W}=0.727, P<0.0001$ for East China). In plotting mean inhibition over year for the Florida isolates, there was a significant weakly negative correlation $(R=-0.352, P=$ $0.0008)$. For the East China isolate collection, correlation of inhibition over time was neither strong nor significant $(R=-0.01, P=$ 0.9100 ) (Fig. 3). The comparison between the regional distributions showed that they were significantly different from each other $(\mathrm{D}=$ 0.755, $P<0.0001$; Fig. 2).

Thiophanate-methyl. Approximately $74 \%$ of Florida isolates (61 of 95) were resistant to thiophanate-methyl compared with $94 \%$ of isolates collected in East China (65 of 69). Twenty-three percent of Florida isolates $(n=20)$ exhibited a sensitive phenotype compared with $6 \%$ of isolates in East China (Fig. 1). The distribution of mean isolate inhibition for both collections revealed that most inhibitions were distributed around $0 \%$. Neither distribution was normally distributed (W $=0.772, P<0.0001$ for Florida; $\mathrm{W}=0.854, P \leq 0.0001$ for East China) and a long tail was present in the Florida distribution. Despite the similar phenotypic results, the distributions were significantly different from each other $(\mathrm{D}=0.253, P=0.0150)$ (Fig. 2$)$, which could be attributed to the long tail toward sensitivity in the Florida distribution. No significant linear correlations were observed for the mean percent inhibition and the year collected $(R=-0.086, P=0.4290$ for Florida; $R$ $=0.050, P=0.6420$ for East China) (Fig. 3).

Difenoconazole. Difenoconazole was only tested in East China. The sensitive phenotype was observed in $97 \%$ of the isolates $(n=$ $67)$, with the remaining $3 \%(n=2)$ being classified as resistant. The highest density of the mean percent inhibition was observed at $60 \%$, with a short tail to the left for the two resistant isolates, which produced a non-normal distribution ( $\mathrm{W}=0.893, P<0.0001)$ (Fig. 4).
No correlation was observed between year collected and mean percent inhibition $(R=0.037, P=0.7580)$.

Difenoconazole and tebuconazole cross-resistance. A Pearson correlation test found a significant positive correlation between tebuconazole and difenoconazole inhibition $(R=0.828, P<0.0001)$. Although these inhibitions between the two fungicides correlated strongly, a McNemar test showed significant differences between phenotypic profiles of difenoconazole and tebuconazole $\left(\chi^{2}=\right.$ 26.04, $P<0.0001)$ and that the distributions between the fungicides were significantly different $(\mathrm{D}=0.507, P<0.0001)$ (Fig. 4).

\section{Discussion}

Fungicide resistance has been and remains a major limitation of GSB field management. Although this topic has been widely investigated in the southeastern United States, this study is unique because it includes another major cucurbit region that supplies a substantial amount of U.S. watermelon seed. Based on these results, fungicide resistance is problematic for multiple classes of fungicides in both locations and production systems. However, the frequency of product resistance in East China tends to be different from Florida isolates. These differences are important for determining how fungicide resistance management strategies will vary between these regions and production systems as well as where resistance monitoring efforts should focus in Florida.

GSB MBC fungicide resistance was reported $>30$ years ago in Greece (Malathrakis and Vakalounakis 1983) and a relatively short time later in the United States (Keinath and Zitter 1998). Thus, even though resistance to thiophanate-methyl in China had not been reported, it was hypothesized that this resistance was present, which was confirmed by this study. Thiophanate-methyl is still commonly
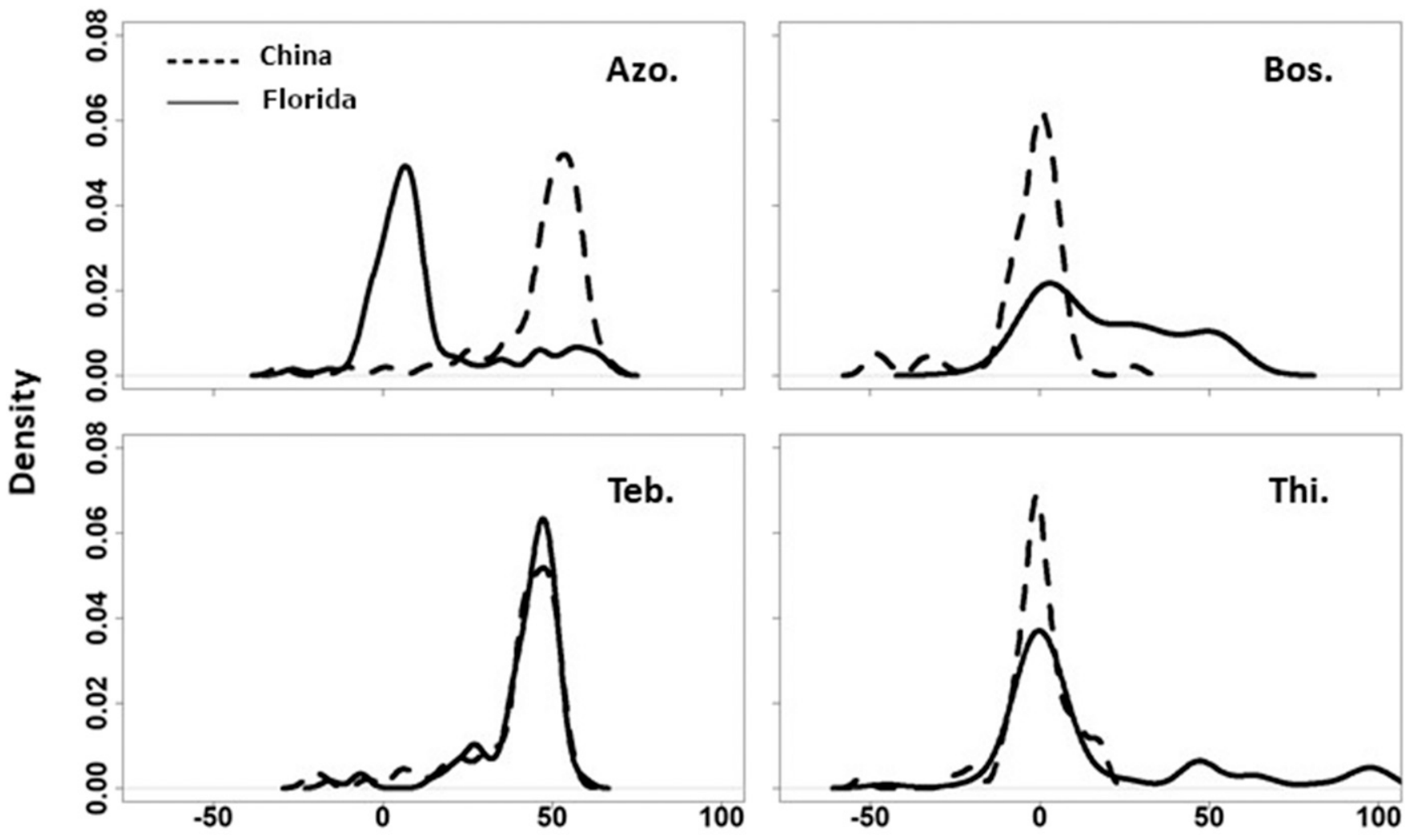

\section{Mean Percent Inhibition}

Fig. 2. Kernel density plots of mean percent inhibition response of the isolates to azoxystrobin (Azo) at $0.096 \mathrm{mg} /$ liter $(\mathrm{D}=0.74, P<0.001)$, boscalid (Bos) at $0.034 \mathrm{mg} / \mathrm{liter}(\mathrm{D}=$ $0.54, P<0.001)$, tebuconazole (Teb) at $0.128 \mathrm{mg} /$ liter $(\mathrm{D}=0.14, P=0.378)$, and thiophanate-methyl (Thi) at $100 \mathrm{mg} /$ liter $(\mathrm{D}=0.25, P=0.010)$ for the Florida (solid line) and East China (dashed line) collections ( $n=95$ and 69 , respectively). To note, the number of Florida isolates equals 89 isolates from Florida and six isolates from Georgia. Inhibition responses were calculated from an amended agar mycelial growth assay $96 \mathrm{~h}$ after inoculation. Density values on the y-axis represent the probability density, which indicates a relative likelihood that a random variable would equal that point. 
used in East China production systems but has a limited use in the Florida open-field systems. Sensitive isolates were only found in the Florida samples. However, correlation analysis indicated that sensitive isolate frequency was not increasing with time, which is similar to East China. It appears that Florida's limited use of
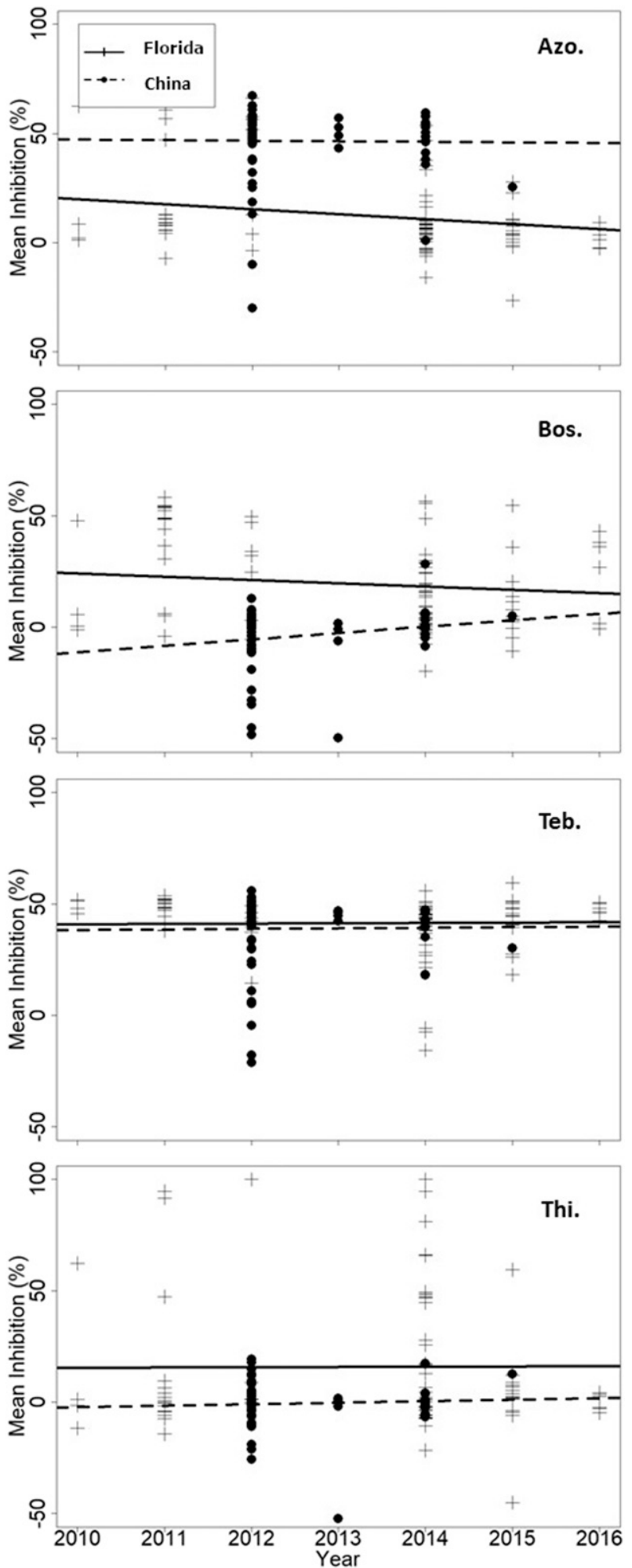

Fig. 3. Linear correlation using the Pearson test for the relationship between percent mycelia inhibition (mean inhibition) and the year the isolates were collected for the fungicides azoxystrobin (Azo), boscalid (Bos), tebuconazole (Teb), and thiophanatemethyl (Thi). The respective correlation statistics are cited in the Results for each product. Sample sizes were 69 and 95 for East China and Florida isolates, respectively. To note, the number of Florida isolates equals 89 isolates from Florida and six isolates from Georgia. thiophanate-methyl has led to the identification of sensitive populations from a relatively small sample size, but the frequency of these populations appears to be stagnant. Based on our results, East China producers should consider eliminating thiophanate-methyl from their GSB and other fungal disease management programs, whereas Florida producers should be extremely judicious (e.g., never apply the product alone, and only apply when necessary or the focus is on other pathogens) if this product's use is continued in watermelon disease management programs (van den Bosch et al. 2014). It is possible that given enough time, sensitive populations of thiophanate-methyl may be identified again in East China. However, it appears unlikely that a substantial percentage ( $>25 \%)$ of Stagonosporopsis spp. populations will become sensitive to this product in both regions again.

Resistance to the SDHI fungicide boscalid is well documented with Stagonosporopsis spp. in the United States (Keinath 2015; Stevenson et al. 2008; Thomas et al. 2012), but the extent of resistance in China is not well known. In our study, almost all of the East China isolates were boscalid resistant, but only about half were resistant in the Florida collection. It was also noted that inhibition to boscalid appears to be decreasing in Florida's population, whereas the pathogen population appears to be static around the resistant phenotype in East China. This suggests that the boscalid resistance profile is near its peak frequency in East China but is currently under directional selection in Florida. Thus, similar to MBC, it is possible that SDHI fungicides may be relatively useful in both production systems, but their use for GSB management should be avoided and they should be used carefully when managing other diseases (e.g., avoid using alone).

Further testing of various SDHI products is needed, as they can vary in their efficacy depending on the resistance mutations present in the population. Since the report of boscalid resistance, other SDHI fungicides such as fluopyram and penthiopyrad have been introduced for use against GSB in the United States (Avenot et al. 2012). There is evidence of Stagonosporopsis spp. cross-resistance between penthiopyrad and boscalid (Thomas et al. 2012), which indicates that other SDHI compounds may not be effective for GSB control. Although cross-resistance is a problem with many SDHI fungicides, fluopyram is still an effective fungicide for GSB control (Avenot et al. 2012), which is consistent with other plant pathogenic organisms (Ishii et al. 2011). Based on the frequency of boscalid resistance in both systems, it is likely that other SDHI fungicides (e.g., penthiopyrad) will see reduced efficacy as well. Limiting the use of this group of fungicides in both regions may be difficult, but mixing them with other groups (e.g., multisite fungicides) may help prolong their effectiveness for GSB management (Elderfield et al. 2018; van den Bosch et al. 2014)

DMI fungicides continue to be effective products for managing GSB (Keinath and Hansen 2013), but tebuconazole resistance was identified for the GSB pathogen S. caricae in 2016 (Li et al. 2016). As observed in this study, the DMI resistant phenotype's presence tends to be low but was observed on S. citrulli for the first time instead of $S$. caricae. Further testing for the DMI resistance genes is needed to determine whether the resistance pattern is the same as that

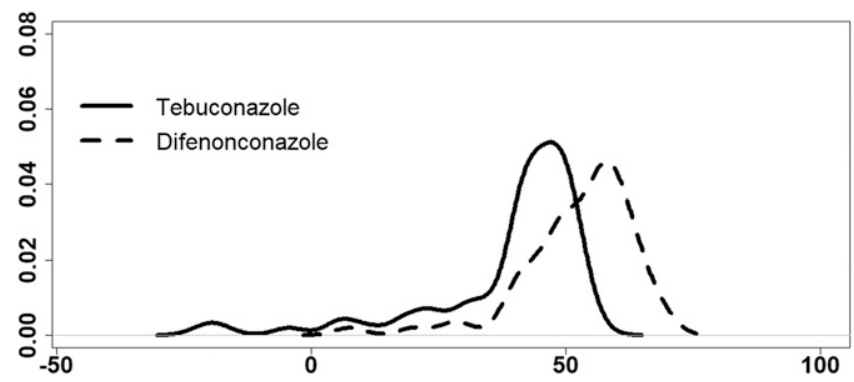

Fig. 4. A kernel density plot of mean tebuconazole and mean difenoconazole inhibitions in the East China collection $(n=69)$. Mean percent inhibition is plotted on the $x$-axis with density plotted on the $y$-axis. Mean tebuconazole inhibition is plotted with a solid line and mean difenoconazole inhibition is plotted with a dashed line. A Kolmogorov-Smirnov test was conducted to compare the two distributions $(\mathrm{D}=0.51, P<0.001)$. 
reported by $\mathrm{Li}$ et al. (2016). In addition, the resistant phenotype frequency does not appear to be increasing in either system, but it may be increasing at a rate not detectable by the current sample sizes. There was also correlation indicating that as tebuconazole inhibition decreases, difenoconazole inhibition also decreases. This finding is consistent with previous studies, in which a significant positive correlation was observed between tebuconazole and difenoconazole for Stagonosporopsis spp. mycelia inhibition (Thomas et al. 2012). Based on these results, there is concern that cross-resistance may be a future limitation to the DMI fungicides. Despite this concern, DMI fungicides remain effective against a majority (>50\%) of the Stagonosporopsis spp. in Florida and East China.

Cross-resistance is not expected in DMI fungicides (Brent and Hollomon 2007); however, our results indicate that cross-resistance may be present for tebuconazole and difenoconazole. Despite this indication, the fungicide inhibition distributions were different with significantly more isolate being resistant to tebuconazole than difenoconazole. The differences in these distributions may be explained by typical usage of these products and/or their commercial sale release date. According to Agrochemex (2012), tebuconazole was first registered for commercial sale in China during 1995 and difenoconazole was released during 1999. Although the difference in release date between the two products is relatively short, the patent for tebuconazole expired first, allowing it to be sold to Chinese producers at a lower price. A similar product release situation occurred in the United States, which would allow us to hypothesize that difenoconazole will also have a shifted mean inhibition distribution compared to tebuconazole there (Thomas et al. 2012). The possible presence of cross-resistance is a concern for the DMI fungicide group and should be taken into consideration for GSB management.

A unique observation in this study was that the sensitive phenotypes observed between the two regions were different for the QoI fungicide azoxystrobin. It was believed that a larger resistant population frequency would be observed in East China compared with Florida because the fungicide was off patent a few years earlier there and use patterns were expected to increase. However, the opposite trend was observed, indicating that the Florida system created a more conducive environment for resistance selection than East China. Resistance was present in East China but in low frequencies producing a long tail distribution, which is an irregular sensitivity distribution for strobilurin fungicide class (Brent and Hollomon 2007). It should also be noted that this assay only consisted of mycelial growth inhibition, and future research should explore spore germination inhibition to confirm these resistant phenotype frequencies. Inhibition to azoxystrobin currently does not appear to be increasing or decreasing in East China. The Florida collection shows the opposite trend, in that the fungicide effectiveness is decreasing over time. However, until the mutation frequencies are known in both systems, it appears that the use of this fungicide alone or frequently should be avoided. Further examination of fungicide usage differences between the two regions is needed to better understand this phenomenon. If this phenomenon is not related to fungicide usage, then another environmental and/or genetic factor may be influencing this selection process. Both populations still have the sensitive phenotype present in different proportions, which also provides unique opportunities for examining fungicide resistance management in multiple spray programs (Elderfield et al. 2018; van den Bosch et al. 2015a, b).

Resistant and sensitive phenotypes were detected for all of the fungicides assessed in this study except for thiophanate-methyl in East China, where only the resistant phenotype was observed. Resistance management guidelines are put forth to ensure that fungicides will be most effective for the longest time possible, and these guidelines are not designed to eliminate resistant phenotypes from a population. This means that the high resistance frequency levels observed in thiophanate-methyl and boscalid, as well as azoxystrobin in Florida, are a concern for future GSB management. It is possible that many producers are already removing these fungicides from their management programs, which will put more selection pressure on the DMI fungicides (e.g., tebuconazole and difenoconazole). This increased pressure is concerning especially because the resistant phenotype was observed in S. citrulli, the dominant Stagonosporopsis species (Brewer et al. 2015; Li and Brewer 2016; Li et al. 2016). Even though thiophanate-methyl, boscalid, and azoxystrobin have resistance problems, there are still sensitive populations left that may make them good mixing partners with other fungicide groups (e.g., DMI), but they should be used judiciously for GSB management and even when management is focused on other fungal diseases (Elderfield et al. 2018; van den Bosch et al. 2014, 2015b). Furthermore, the addition of a multisite fungicide, such as chlorothalonil or mancozeb, will be an important strategy for both regions' management programs to help limit resistance and provide quality GSB control (Zhou and Everts 2008). These data provide a foundation for developing fungicide programs that can effectively manage GSB based on the production system's estimated resistance frequency. However, continued monitoring and surveying is needed to understand how changes to fungicide usage will affect resistance frequency and disease control efficacy. It will also be important to expand population sampling to the western regions of China where a majority of its seed production occurs, and to examine the pathogen populations for the presence of known resistance mutations (e.g. G143A and F129L). GSB is not the only disease cucurbit producers manage in their production systems, but this information about management of GSB with fungicides will be useful for an integrated pest management program.

\section{Literature Cited}

Agresti, A. 2007. McNemar Test Comparing Marginal Proportions. Page 345 in: Categorical Data Analysis. Wiley, New York.

Agrochemex. 2012. More registration of tebuconazole in China. China Agrochemicals, July 2012. http://www.agrochemex.org/wp-content/uploads/ 2012/08/2012-JULY.pdf

Avenot, H. F., Thomas, A., Gitatis, R. D., Langston, D. B., and Stevenson, K. L. 2012. Molecular characterization of boscalid- and penthiopyrad-resistant isolates of Didymella bryoniae and assessment of their sensitivity to fluopyram. Pest Manag. Sci. 68:645-651.

Babu, B., Kefialew, Y. W., Li, P.-F., Yang, X.-P., George, S., Newberry, E., Dufault, N., Ayalew, A., Marois, J., and Paret, M. L. 2015. Genetic characterization of Didymella bryoniae infecting watermelon and other cucurbits in Florida and Georgia. Plant Dis. 99:1488-1499.

Brent, K. J., and Hollomon, D. W. 2007. Fungicide Resistance in Crop Pathogens: How Can It Be Managed? Vol. 1, 2nd ed. Fungicide Resistance Action Committee, Brussels, Belgium.

Brewer, M. T., Rath, M., and Li, H.-X. 2015. Genetic diversity and population structure of cucurbit gummy stem blight fungi based on microsatellite markers. Phytopathology 105:815-824.

Café-Filho, A. C., Santos, G. R., and Laranjeria, F. F. 2010. Temporal and spatial dynamics of watermelon gummy stem blight epidemics. Eur. J. Plant Pathol. 128:473-482

Chakravarti, I. M., Laha, R. G., and Roy, J., eds. 1967. Statistical inference. Pages 392-394 in: Handbook of Methods of Applied Statistics, Vol. I. John Wiley \& Sons, New York, NY.

Chiu, W. F. 1949. Physiology and pathogenicity of the cucurbit black-rot fungus (Key No. Wis.-176). J. Agric. Res. 78:589.

Chiu, W. F., and Walker, J. C. 1949. Morphology and variability of the cucurbit black-rot fungus. J. Agric. Res. 78:83-102.

Conover, W. J. 1999. Practical Nonparametric Statistics, 3rd ed. John Wiley \& Sons, New York, NY.

Elderfield, J. A. D., Lopez-Ruiz, F. J., van den Bosch, F., and Cunniffe, N. J. 2018 Using epidemiological principles to explain fungicide resistance management tactics: Why do mixtures outperform alternations? Phytopathology.108: 803-817.

Elwakil, W. M., Dufault, N. S., Freeman, J. H., and Mossler, M. A. 2017. Florida crop/pest management profile: Watermelon. Electronic Data Information Source CIR1236. University of Florida, Gainesville. http://edis.ifas.ufl.edu/ pdffiles/PI/PI03100.pdf

Gusmini, G., Song, R., and Wehner, T. 2005. New sources of resistance to gummy stem blight in watermelon. Crop Sci. 45:582-588.

Hopkins, D. L., Thompson, C. M., Holgren, J., and Lovie, B. 2003. Wet seed treatment with peroxyacetic acid for the control of bacterial fruit blotch and other seedborne diseases of watermelon. Plant Dis. 87:1495-1499.

Ishii, H., Miyamoto, T., Ushio, S., and Kakishima, M. 2011. Lack of crossresistance to a novel succinate dehydrogenase inhibitor, fluopyram, in highly boscalid-resistant isolates of Corynespora cassiicola and Podosphaera xanthii. Pest Manag. Sci. 67:474-482.

Keinath, A. P. 2000. Effect of protectant fungicide application schedules on gummy stem blight epidemics and marketable yield of watermelon. Plant Dis. 84:254-260.

Keinath, A. P. 2002. Survival of Didymella bryoniae in buried watermelon vines in South Carolina. Plant Dis. 86:32-38. 
Keinath, A. P. 2009. Sensitivity to azoxystrobin in Didymella bryoniae isolates collected before and after field use of strobilurin fungicides. Pest Manag. Sci. 65:1090-1096.

Keinath, A. P. 2011. From native plants in central Europe to cultivated crops worldwide: The emergence of Didymella bryoniae as a cucurbit pathogen. HortScience 46:532-535.

Keinath, A. P. 2015. Baseline sensitivity of Didymella bryoniae to cyprodinil and fludioxonil and field efficacy of these fungicides against isolates resistant to pyraclostrobin and boscalid. Plant Dis. 99:815-822.

Keinath, A. P., and DuBose, V. B. 2017. Disinfectant treatments that reduce transmission of Stagonosporopsis citrulli during grafting. Plant Dis. 101: 1895-1902.

Keinath, A. P., and Hansen, Z. R. 2013. Isolates of Didymella bryoniae from South Carolina remain sensitive to DMI fungicides despite multiyear exposure. J. Phytopathol. 161:315-323.

Keinath, A. P., and Zitter, T. A. 1998. Resistance to benomyl and thiophanatemethyl in Didyella bryoniae from South Carolina and New York. Plant Dis. 82:479-484.

Kothera, R. T., Keinath, A. P., Dean, R. A., and Farnham, M. W. 2003. AFLP analysis of a worldwide collection of Didymella bryoniae. Mycol. Res. 107: 297-304.

Lee, D. H., Mathur, S. B., and Neergaard, P. 1984. Detection and location of seedborne inoculum of Didymella bryoniae and its transmission in seedlings of cucumber and pumpkin. Phytopathology 109:301-308.

Li, H. X., and Brewer, M. T. 2016. Spatial genetic structure and population dynamics of gummy stem blight fungi within and among watermelon fields in the Southeastern United States. Phytopathology 106:900-908.

Li, H. X., Stevenson, K. L., and Brewer, M. T. 2016. Differences in sensitivity to a triazole fungicide among Stagonosporopsis species causing gummy stem blight of cucurbits. Plant Dis. 100:2106-2112.

Li, P., Ren, R., Yao, X., Xu, J., Babu, B., Paret, M., and Yang, X. 2014. Identification and characterization of the causal agent of gummy stem blight from muskmelon and watermelon in East China. J. Phytopathol. 163:314-319.

Malathrakis, N. E., and Vakalounakis, D. J. 1983. Resistance to benzimidazole fungicides in the gummy stem blight pathogen Didymella bryoniae on cucurbits. Plant Pathol. 32:395-399.

Pan, H. 2015. Insecticides promote viral outbreaks by altering herbivore competition. Ecol. Appl. 25:1585-1595.

Paret, M. L., Dufault, N. S., Newark, M., and Freeman, J. H. 2014. Management of gummy stem blight (black rot) on cucurbits in Florida. Document PP280. University of Florida Institute of Food and Agricultural Sciences Extension, Gainesville. http://edis.ifas.ufl.edu/pp280
R Core Team. 2015. R: A language and environment for statistical computing. R Foundation for Statistical Computing, Vienna, Austria. https://www.R-project.org/ Royston, P. 1982a. Algorithm AS 181: The W test for normality. Appl. Stat. 31 176-180.

Royston, P. 1982b. An extension of Shapiro and Wilk's W test for normality to large samples. Appl. Stat. 31:115-124.

Sedgwick, P. 2012. Pearson's correlation coefficient. BMJ 345:e4483.

Sitterly, W. R., and Keinath, A. P. 1996. Gummy stem blight. Pages 27-28 in: Compendium of Cucurbit Diseases. T. A. Zitter, D. L. Hopkins, and C. E. Thomas, eds. American Phytopathological Society, St. Paul, MN.

Stevenson, K. L., Langston, D. B., Jr., and Sanders, F. 2008. Baseline sensitivity and evidence of resistance to boscalid in Didymella bryoniae. Phytopathology 98:S151.

Stevenson, K. L., Langston, D. B., and Seebold, K. W. 2004. Resistance to azoxystrobin in gummy stem blight pathogen documented in Georgia. Online publication. Plant Health Prog. 5. doi: 10.1094/PHP-2004-1207-01-RS.

Stewart, J. E., Turner, A. N., and Brewer, M. T. 2015. Variation in host range in the Didymella bryoniae/Stagonosporopsis caricae species complex pathogenic to cucurbits and papaya. Fungal Biol. 119:370-382.

Sudisha, J., Niranjana, S. R., Umesha, S., Prakash, H. S., and Shetty, H. S. 2006. Transmission of seed-borne infection on muskmelon by Didymella bryoniae and effect of seed treatments on disease incidence and fruit yield. Biol. Control 37:196-205.

Thomas, A., Langston, D. B., and Stevenson, K. L. 2012. Baseline sensitivity and cross-resistance to succinate-dehydrogenase inhibiting and demethylationinhibiting fungicides in Didymella bryoniae. Plant Dis. 96:979-984.

van den Bosch, F., Fraaije, B., Oliver, R., van den Berg, F., and Paveley, N. 2015a. The use of mathematical models to guide fungicide resistance management decisions. Pages 49-62 in: Fungicide Resistance in Plant Pathogens. H. Ishii and D. Hollomon, eds. Springer, Tokyo, Japan.

van den Bosch, F., Oliver, R., van den Berg, F., and Paveley, N. 2014. Governing principles can guide fungicide-resistance management tactics. Annu. Rev. Phytopathol. 52:175-195.

van den Bosch, F., Paveley, N., Fraaije, B., van den Berg, F., and Oliver, R. 2015b. Evidence-based resistance management: a review of existing evidence. Pages 63-76 in: Fungicide Resistance in Plant Pathogens. H. Ishii and D. Hollomon, eds. Springer, Tokyo, Japan.

Xu, R., Kuang, R., Pay, E., Dou, H., and de Snoo, G. R. 2008. Factors contributing to overuse of pesticides in western China. Environ. Sci. 5:235-249.

Zhou, X.-G., and Everts, K. L. 2008. Integrated management of gummy stem blight of watermelon by green manure and Melcast-scheduled fungicides. Online publication. Plant Health Prog. 9. doi: 10.1094/PHP-2008-1120-01-RS 